\title{
O desenvolvimento de capacidades linguageiras: análise de sequência didática do gênero artigo de opinião no Ensino Médio Noturno
}

\section{The development of language abilities: analysis of the didactic sequence of the genre of opinion in late-night High School}

\author{
Rosalina Dantas da Silva* \\ Universidade Federal da Grande Dourados, Dourados, MS, Brasil \\ Adair Vieira Gonçalves ${ }^{* *}$ \\ Universidade Federal da Grande Dourados, Dourados, MS, Brasil
}

\begin{abstract}
Resumo: Esta pesquisa está inserida no campo aplicado dos estudos da linguagem e tem como objetivo geral avaliar como uma sequência didática foi recontextualizada numa turma do terceiro ano noturno do Ensino Médio de uma escola pública estadual localizada em Dourados, Mato Grosso do Sul. A sequência didática foi produzida colaborativamente por duas professoras: uma que atuou como colaboradora e a outra como pesquisadora. Os objetivos específicos desta pesquisa são: analisar a sequência didática no que se refere à distribuição das capacidades de linguagem e analisar o desenvolvimento das capacidades linguageiras dos alunos em relação à escrita do gênero artigo de opinião, depois da didatização da sequência didática, por meio das produções iniciais e finais. A pesquisa está embasada nos pressupostos téorico-metodológicos do interacionismo sociodiscursivo (Bronckart, 2006; 2007), consubstanciada nas teorias advindas da escola genebrina (Schneuwly; Dolz; Noverraz, 2004). Metodologicamente, trata-se de uma pesquisa qualitativa, de cunho documental. Constituem o corpus a sequência didática, produções iniciais e finais dos alunos. Os resultados finais, definidos a partir da avaliação da sequência didática e das produções dos alunos, mostram que os alunos avançaram significativamente na capacidade linguístico-discursiva, mas apenas relativamente nas capacidades de ação e discursiva.
\end{abstract}

Palavras-chave: Sequência didática. Capacidades de linguagem. Artigo de opinião.

\begin{abstract}
This research is inserted in the applied field of language studies and has as general objective to evaluate how a didactic sequence was recontextualized in a class of the third year of secondary school in a state public school located in Dourados, Mato Grosso do Sul. The didactic sequence was produced collaboratively by two teachers: one who worked as a collaborator and the other as a researcher. The specific objectives are: to analyze the didactic sequence with regard to the distribution of language abilities and to analyze the development of the pupils' linguistic abilities in relation to the writing of the genre of opinion, after the didacticization of the didactic sequence, through the initial and final productions. The research is based on the theoretical-methodological assumptions
\end{abstract}

\footnotetext{
* Mestre em Letras, revisora de textos da Universidade Federal da Grande Dourados, Dourados, MS, Brasil; rosalina.silva@ufgd.edu.br

** Professor doutor na Faculdade de Comunicação, Artes e Letras da Universidade Federal da Grande Dourados, Dourados, MS, Brasil; adairgoncalves@uol.com.br
} 
of socio-discursive interactionism (Bronckart, 2006, 2007), embodied in the theories of the Geneva school (Schneuwly; Dolz; Noverraz, 2004). Methodologically, this is a qualitative, documentary research. The corpus is constituted by didactic sequences, initial and final productions of the students. The final results, defined from the evaluation of the didactic sequence and the pupils' productions, show that the students advanced significantly in the linguisticdiscursive capacity, but only relatively in the capacities of action and discursive.

Keywords: Didactic sequence. Language skills. Opinion article.

\section{INTRODUÇÃo}

A produção textual na Educação Básica é um dos mais importantes eixos no ensino de Língua Portuguesa e tema frequente de pesquisas da área de Linguística Aplicada (Lopes-Rossi, 2012). Ferraz, em $2012^{2}$, realizou ampla pesquisa envolvendo professores do município de Dourados, Mato Grosso do Sul. Primeiramente, foi realizada a formação teórico-prática (com carga horária total de 140 horas), apoiandose na epistemologia do interacionismo sociodiscursivo (ISD) e em propostas defendidas por pesquisadores da Didática de Ensino de Línguas da Universidade de Genebra, sobretudo Schneuwly e Dolz (2004). Em seguida, foi feita a mediação de dois professores para a etapa da transposição didática externa (total de 32 horas e 24 minutos): modelização do gênero artigo de opinião, planificação, elaboração e desenvolvimento da sequência didática. Finalmente, foram investigadas as representações dos professores a respeito da prática pedagógica por gêneros textuais e sequência didática (doravante $\mathrm{SD}$ ).

$\mathrm{Na}$ pesquisa de Ferraz (2012), entretanto, não foram analisados os resultados do processo de ensino-aprendizagem, mediado pela SD. Esta etapa é importante, dentre outros motivos, porque a SD foi construída a partir do mapeamento das dificuldades dos estudantes de determinada turma do Ensino Médio de uma escola pública. Decorrente disso, neste artigo procuramos investigar a SD produzida por uma professora pesquisadora (PP) e uma professora colaboradora (PC).

O corpus da pesquisa é estritamente documental, composto por 46 horas-aula de gravação, além da sequência de atividades escritas, produções iniciais e finais de nove alunos (número de estudantes que participaram de todo o processo de intervenção didática por meio da SD). Com todos esses registros, construímos uma sinopse $^{3}$ da SD, a partir da interpretação dos vídeos e da sequência de atividades escritas voltadas para o aluno.

Em resumo, este artigo traz resultados de uma investigação realizada em um ambiente público de escolarização ( $3^{\circ}$ ano do Ensino Médio noturno), com o

\footnotetext{
2 Damos continuidade à investigação de caráter colaborativo-intervencionista, consubstanciada numa pesquisa-ação, de natureza qualitativa, realizada por Ferraz (2012), analisando, neste momento, os elementos da transposição didática.

${ }^{3}$ A sinopse é uma ferramenta desenvolvida por Dolz, Ronveaux e Schneuwly (2006) que permite organizar e sistematizar os objetos de ensino durante as aulas. Nesta pesquisa, a sinopse nos permitiu definir a maneira pela qual as professoras organizaram o ensino-aprendizagem durante a didatização da SD. O processo de construção da sinopse será descrito na seção dos aspectos metodológicos.
} 
propósito de apresentar, a partir da análise de uma experiência com SD do gênero artigo de opinião, o desenvolvimento de capacidades de linguagem dos alunos.

\section{SD: UM PROCEDIMENTO METODOLÓGICO}

Para Dolz, Noverraz e Schneuwly (2004), a SD é um procedimento metodológico para o ensino-aprendizagem de um determinado gênero textual oral ou escrito. Por meio das $\mathrm{SD}^{4}$, os alunos podem dominar melhor um gênero, isso significa escrever, escutar, ler e/ou falar de modo mais adequado em dada situação comunicativa. A longo prazo, um ensino organizado em SD "deve permitir aos alunos um acesso progressivo e sistemático aos instrumentos comunicativos e linguísticos necessários à produção de textos pertencentes a diferentes gêneros orais e escritos" (Cordeiro; Azevedo; Mattos, 2004, p. 31).

Segundo Dolz, Noverraz e Schneuwly (2004), a SD é constituída de quatro etapas: apresentação da situação, produção inicial, desenvolvimentos dos módulos e produção final. A primeira etapa, que é a apresentação da situação, refere-se à exposição de um projeto de comunicação aos alunos que será realizado verdadeiramente na produção final. Trata-se de um mapeamento das capacidades de linguagem ${ }^{5}$ dominadas pelos estudantes. Nesta fase, torna-se fundamental a realização de duas dimensões: apresentação de um problema de situação bem definido e a preparação dos conteúdos dos textos que serão produzidos.

A segunda etapa de uma SD é a produção inicial, ou seja, o primeiro lugar do ensino-aprendizagem. Nessa produção, os alunos evidenciam o que sabem a respeito do gênero selecionado. Com esses textos, o docente consegue notar as capacidades desenvolvidas e pode planejar as intervenções a serem feitas para promover o desenvolvimento das potencialidades. Com o diagnóstico da primeira produção, o professor estabelece a quantidade de módulos que serão necessários.

A terceira etapa é o desenvolvimento dos módulos e nela devem ser desenvolvidas as capacidades de linguagem. Nos módulos, é preciso trabalhar os elementos que surgem como desafios da produção textual na primeira produção e, por consequência, dar aos alunos os instrumentos necessários para superá-los.

A última etapa da SD é a produção final; espera-se que nela o estudante coloque em prática o que aprendeu no decorrer das demais etapas da SD. É atribuído ao aluno o papel de regulador de seu próprio comportamento no processo de revisão e reescrita do texto ${ }^{6}$. A produção final é a elaboração de um texto que deve circular socialmente, de acordo com os destinatários pretendidos e previstos no modelo didático do gênero.

\footnotetext{
${ }^{4}$ A SD é construída após o modelo didático que é uma ferramenta necessária elaborada pelo professor e consiste na descrição das principais características do gênero textual e na identificação de suas dimensões ensináveis.

${ }^{5}$ Para conceitualizar a ação de linguagem, Dolz e Schneuwly (2004), na perspectiva do ISD, construíram um quadro teórico em que as capacidades de linguagem são classificadas em três tipos: de ação, discursivas e linguístico-discursivas. Cabe salientar que essas capacidades de linguagem estão em constante intersecção e só são separadas para fins didáticos.

${ }^{6}$ No esquema geral de uma SD proposto por Barros (2012, p. 79), adaptado de Dolz, Noverraz e Schneuwly (2004), a autora acrescenta a etapa "o processo de reescrita textual” depois da "produção
} 
Diante do exposto, a SD é vista como uma possibilidade de procedimento metodológico para a formação de leitores e produtores de textos. Nessa proposta de ensino-aprendizagem dos gêneros são dadas condições aos alunos que os façam refletir sobre o conhecimento já adquirido e isso proporciona que eles reelaborem suas ideias e textos. Não podemos deixar de salientar a função mediadora que o professor adota, por ser atribuída a ele a responsabilidade tanto de diagnosticar o que os alunos já sabem quanto de intervir durante todo o processo de transposição didática interna.

\section{Aspectos METOdológicos DA PESQUISA}

Esta pesquisa está inserida nos estudos aplicados da linguagem, investiga o uso da linguagem e o consequente desenvolvimento de capacidades linguageiras na didatização de uma sequência didática do gênero artigo de opinião, numa $3^{a}$ série do Ensino Médio, do período noturno. Analisamos, portanto, a prática de um professor, na condição de pesquisador, e um professor colaborador, mediados pela SD. Este trabalho está inserido em um paradigma qualitativo ${ }^{7}$. Dado o enfoque no conteúdo e na didatização dos objetos de ensino, a perspectiva desta pesquisa está centrada na análise documental.

A partir da análise dos vídeos das aulas de transposição didática, dividimos a carga horária utilizada, conforme os objetos de ensino. Dessa forma, conseguimos calcular quanto tempo (h/a) foi utilizado para cada objeto de ensino e para cada módulo da SD. A partir daí, classificamos quais capacidades de linguagem foram mobilizadas no decorrer de cada aula. Sendo assim, foi possível obter o tempo gasto para cada capacidade de linguagem na SD e por módulo. Em seguida, confrontamos esses registros de interpretação dos vídeos com o que constava na sequência de atividades escritas. Identificamos os objetos de ensino e as atividades trabalhadas para construirmos a sinopse.

A sinopse foi construída após as análises das 46h/a gravadas (trabalho realizado) e da SD (trabalho planificado). De modo interpretativo, demos destaque para os títulos das atividades, objetivos para as professoras, instrumentos de interação, capacidades de linguagem implicadas no processo e quantitativo de horas/aula para didatização. Dividimos as análises por módulos I, II, III, IV e V e observamos como os objetos de ensino estavam organizados no dispositivo escrito, confrontados com a gravação das aulas. Concluído o mapeamento das capacidades linguageiras investigadas nas produções escritas, passamos a comparar as duas versões dos artigos de opinião produzidos para notar o avanço ou não dos alunos depois da SD.

\footnotetext{
final", desmembrando a última etapa proposta pelos pesquisadores europeus. Nessa última etapa, Barros esquematiza três pontos a serem seguidos, a saber: "1) Estratégias de autoavaliação e/ou avaliação em pares e/ou avaliação coletiva; 2) Momento em que o trabalho com as questões mais formais da língua pode ter um resultado mais satisfatório e 3) Completar a interação, enviando os textos aos destinatários”.

7 “A Linguística Aplicada no Brasil é quase totalmente de natureza qualitativa, com preocupações com o idiossincrático, o particular e o situado” (Moita Lopes, 2013, p. 17). Esta pesquisa é apoiada, essencialmente, na interpretação dos significados contidos em um determinado contexto. Dessa forma, traduz e expressa o sentido dos fenômenos do mundo social, reduzindo a distância entre a teoria e os dados coletados, entre o contexto e a ação pedagógica.
} 
Pela sinopse, pudemos identificar os acontecimentos que comprometeram a transposição didática interna da SD. Isso porque o objetivo da ferramenta foi sistematizar a SD e revelar as facetas da (re)construção dos objetos de ensino. Nesse sentido, utilizamos a sinopse como ferramenta de interpretação das produções iniciais e finais, para que pudéssemos notar quais reflexos da didatização da SD aparecem na escrita dos alunos.

A segunda etapa do trabalho foi a análise qualitativa das produções iniciais, observando aspectos contextuais, discursivos e linguístico-discursivos que cada aluno dominava, dominava parcialmente e não dominava. Diante desses dados, analisamos qualitativamente as produções finais, após a didatização da SD, mantendo o foco de investigação na mobilização das capacidades de linguagem.

\section{O CONTEXTO DE PRODUÇÃO DA SD DO GÊNERO ARTIGO DE OPINIÃO: UMA EXPERIÊNCIA}

A apresentação da situação, primeira etapa da SD desta pesquisa, aconteceu quase um mês antes do início do desenvolvimento dos módulos da SD. Diferentemente das orientações recebidas durante o curso de formação continuada ${ }^{8}$, a PC não especificou um contexto de produção determinado para que os alunos elaborassem a primeira produção. Isso significa que os alunos não foram orientados segundo uma situação comunicativa.

Para a apresentação da situação no contexto de ensino-aprendizagem, a PC apenas definiu o gênero: o artigo de opinião. Isso significa que não houve preparação dos alunos para a produção inicial como também não lhes foi apresentado o objetivo do projeto de comunicação a ser realizado posteriormente. Convém salientar que, quando há uma situação de comunicação bem definida, pressupõe-se que os alunos consigam responder em certa medida à contextualização dada, ainda que não sejam respeitadas todas as características do gênero solicitado.

\subsection{Produção inicial: análise do primeiro encontro com o gênero}

A primeira produção, de caráter diagnóstico, foi a escrita de um artigo de opinião com limite de linhas: no mínimo 15 e no máximo 30 (Ferraz, 2012), solicitado aos alunos pela PC. O objetivo principal dessa atividade foi mapear as capacidades de linguagem dominadas pelos estudantes a respeito do gênero artigo de opinião. Sem definição do tema, os alunos produziram artigos de opinião sobre drogas, aborto, preconceito racial, educação, violência, bullyng, discriminação, entre outros.

\footnotetext{
${ }^{8} \mathrm{Fez}$ parte das atividades da formação continuada oferecida pela PP a vários professores, inclusive à PC, a esquematização da SD em que constava um momento didático específico destinado à apresentação da situação, etapa essencial da SD. Cabe ressaltar que durante o curso tais esquemas foram avaliados pela PP e essas avaliações geraram tanto sugestões no corpo do material quanto bilhetes orientadores aos professores cursistas. Ferraz (2012, p. 180) afirma que "durante a formação de professores, no contexto da pesquisa, a produção inicial foi um ponto polêmico até o entendimento de que ela, ainda que inicial, deve ser orientada pelo contexto de produção, isto é, uma situação de comunicação definida que estimula e facilita a produção textual”.
} 
Dada a diversidade temática, a PC e a PP observaram que seria mais difícil trabalhar atividades para o desenvolvimento da capacidade discursiva (principal dificuldade detectada na produção inicial). Sendo assim, foi proposta aos alunos temática única. Por votação, os alunos decidiram tratar do assunto drogas, o mais recorrente nas produções iniciais. Aos 17 alunos que haviam escrito sobre outros temas, a PC solicitou nova produção.

Inicialmente, foi acordado entre as professoras que a análise da produção inicial seria feita, em momentos distintos, pela PC e posteriormente pela PP. Por falta de tempo, a PC iniciou a avaliação, mas não terminou. A PP concluiu a atividade avaliativa e sistematizou o quadro das capacidades de linguagem.

$\mathrm{Na}$ avaliação dos textos, foi utilizado um quadro de análise, categorizado da seguinte forma: D - domina; DP - domina parcialmente e ND - não domina. Convém salientar que os aspectos observados foram resultantes do modelo teórico do gênero, sem perder de vista as capacidades de linguagem e as dimensões ensináveis do artigo de opinião.

Da análise da capacidade de ação, foi possível depreender, pelas primeiras produções, que grande parte dos alunos assumiu parcialmente a posição discursiva de articulista. Entretanto, demonstraram dificuldade no desenvolvimento das opiniões. A temática das drogas não foi problematizada na discursividade do texto; com argumentos previsíveis e pouco organizados as produções não convenciam e, portanto, não eram verdadeiros artigos de opinião.

Quanto ao domínio do gênero em relação à capacidade discursiva, a principal dificuldade estava na capacidade dos alunos de argumentar e de expressar pontos de vista. Constatou-se, ainda, que os alunos tiveram dificuldade na elaboração de premissas bem como na contextualização. Em relação à capacidade linguísticodiscursiva, foi possível observar que os alunos tiveram dificuldade de marcar outras vozes nos textos. Por outro lado, houve domínio relativo no uso de conectivos e anáforas, além dos elementos de conteúdo formal.

No processo diagnóstico da produção inicial, foram encontradas as dificuldades mais recorrentes relacionadas à escrita do artigo de opinião. Tal diagnóstico inicial foi fundamental para o desenvolvimento da SD, pois, por meio dele, foi possível estabelecer o quantitativo de módulos e as atividades da SD, a fim de que o processo de transposição didática interna oferecesse condições para os alunos escreverem com mais proficiência o gênero didatizado.

\subsection{Apresentação e análise dos módulos da SD}

A SD em análise possui sessenta páginas, está dividida em cinco módulos que, por sua vez, estão organizados em atividades. No total, a SD contém dezessete atividades, além de uma parte introdutória denominada "Palavras Iniciais".

A partir da análise do trabalho realizado e planificado, foi construída a sinopse explicitada no Quadro Sinopse dos módulos da sequência didática do gênero artigo de opinião (cf. Anexos), a seguir, conforme os módulos: "conhecendo o artigo de opinião"; "detalhando o artigo de opinião"; "explorando a linguagem do artigo de opinião"; 
"revisando o artigo de opinião" e "publicação do artigo de opinião". Quanto ao cabeçalho dos quadros da sinopse, cabe esclarecer que:

a) Os títulos das atividades ( $1^{\mathrm{a}}$ coluna) foram retirados da SD;

b) Os objetivos das professoras para os alunos e as atividades são advindos de análises e interpretações, destes pesquisadores, tanto da SD como dos vídeos das aulas;

c) As capacidades de linguagem implicadas são resultados de análises embasadas no quadro teórico proposto em Schneuwly e Dolz (2004) e,

d) Horas/aula refletem a somatória de aulas utilizadas na didatização de determinados objetos de ensino, sem a pretensão de exatidão, uma vez que os procedimentos de análise são do âmbito da linguagem e ensino.

Foi possível observar que os acontecimentos diversos (feriados, condições climáticas, por exemplo) comprometeram a transposição didática da SD, alterando a rotina escolar. A questão do tempo escolar também foi sentida pelos alunos. Em linhas gerais, a SD em análise tem seus módulos bem estruturados e segue as concepções teóricas de sustentação do procedimento SD.

Em termos quantitativos, é possível verificar que as três capacidades de linguagem foram mobilizadas na SD. Foi dada ênfase pelas PP e PC à capacidade discursiva tanto no que se refere ao número de atividades quanto na carga horária utilizada em detrimento das demais. A capacidade discursiva está presente em, aproximadamente, $87 \%$ da carga horária total da SD e o enfoque na capacidade discursiva pode ser justificado pelo diagnóstico inicial da turma investigada.

Há grande variação de estratégias nos exercícios e as atividades são diversificadas. Nos módulos, há atividades de observação e análise de diferentes gêneros com ênfase em artigos de opinião, tarefas simplificadas de produção de texto, montagem de painéis, debates, pesquisas na internet e seis atividades virtuais (para a realização desses exercícios foi utilizada a sala de tecnologia da escola). Convém ressaltar que a variedade das atividades pode envolver mais os estudantes nas atividades e os objetos de ensino podem tornar-se mais significativos e contextualizados.

Outro ponto favorável na SD analisada foi a questão polêmica trabalhada durante as aulas: descriminalização da maconha e legalização das drogas. Esse assunto permitiu a aproximação do objeto de ensino a uma questão contemporânea e complexa, sobretudo quando consideramos que a faixa etária dos alunos variava de 16 a 25 anos, idades de grande propensão ao consumo de drogas ${ }^{9}$. Diversos pontos de vista foram trazidos para a sala de aula, argumentos favoráveis e contrários, conhecimento científico sobre os efeitos da maconha, origem geográfica, formas de

\footnotetext{
${ }^{9}$ Segundo o VI Levantamento Nacional sobre o Consumo de Drogas Psicotrópicas entre Estudantes do Ensino Fundamental e Médio das Redes Pública e Privada de Ensino nas 27 Capitais Brasileiras (2010), produzido pela Secretaria Nacional de Políticas sobre Drogas (SENAD), o uso maior da maconha é registrado entre jovens adultos de 18 a 24 anos de idade, atingindo a porcentagem de $17 \%$ nessa faixa etária. Entre adolescentes de 12 a 17 anos o percentual é de 4,1\%. [citado 12 fev. 2019]. Disponível em: http://www.obid.senad.gov.br/portais/OBID/biblioteca/documentos/Publicacoes/328890.pdf.
} 
uso no Brasil e no mundo e posicionamento jurídico. Apesar de ser dada mais evidência à descriminalização da maconha, outros assuntos polêmicos também foram trabalhados na SD, a saber: violência, redução da maioridade penal, pena de morte, cidadania, política, tráfico de drogas, uso de álcool e de cigarro e liberdade de expressão.

\section{ANÁLISE DA EXPERIÊNCIA COM SD DE GÊNERO NO ENSINO MÉDIO NOTURNO}

Nesta seção, apresentaremos os indícios do ensino-aprendizagem e do desenvolvimento dos alunos pela comparação das produções realizadas antes da intervenção da SD (produção inicial) e das produções finais, considerando as capacidades de linguagem como categorias de análise.

As análises foram centradas nas capacidades de linguagem mobilizadas nas produções dos nove alunos. É necessário mencionarmos o contexto de produção, a fim de facilitar a leitura analítica. Temos, assim:

Quadro 1- O contexto de produção do gênero artigo de opinião.

Questão motivadora: Descriminalização da maconha ou legalização das drogas.

Emissor: adolescentes de 16 a 19 anos $^{10}$.

Agente-produtor ${ }^{11}$ : estudantes do $3^{\circ}$ ano do Ensino Médio noturno.

Receptor: visitantes do blog da escola e pessoas que concretamente leiam o texto.

Destinatário: professor, alunos e leitores virtuais.

Objetivo: emitir a opinião sobre o tema descriminalização da maconha ou legalização das drogas.

Espaço e tempo da produção inicial: uma escola estadual de ensino; 45 minutos, tempo de uma aula de Língua Portuguesa no período noturno.

Lugar social: instituição de ensino.

\footnotetext{
${ }^{10}$ Embora tenhamos apontado anteriormente que a faixa etária dos alunos na turma pesquisada variava de 16 a 25 anos, neste momento, estamos considerando apenas a idade dos nove alunos cujos textos são analisados.

11 Conforme Bronckart (2007, p. 95), “[...] a instância responsável pela produção de um texto é uma entidade única (salvo casos raros de co-escritura), que deve ser definida, ao mesmo tempo, de um ponto de vista físico e de um ponto de vista sociosubjetivo. Portanto, poderíamos chamar essa entidade de emissor-enunciador, mas, para simplificar, usaremos a expressão agente produtor ou, mais simplesmente, ainda, o termo autor". Nesta pesquisa, portanto, o termo 'agente-produtor' significa o sujeito responsável pela produção do texto. Esse sujeito é entendido em seu aspecto físico, ser humano real, e em seu aspecto sociossubjetivo, instância social que executa a ação de linguagem. No caso de um artigo de opinião, quem o assina é o agente-produtor físico; quem articula a opinião, defendendoa e/ou refutando outras é o agente-produtor sociossubjetivo, ou enunciador, na perspectiva da Linguística da enunciação (Ferraz, 2012).
} 
Espaço e tempo da produção final: uma escola estadual de ensino; 90 minutos, tempo de duas aulas de Língua Portuguesa no período noturno. No entanto, dado o fim do ano letivo, alguns alunos iniciaram a reescrita na sala de aula e concluíram como "tarefa de casa"; nestes casos, não é possível mensurar o tempo da produção final.

Lugar social: instituição de ensino e, em alguns casos por hipótese, a residência do aluno.

Circulação: Irrestrita, tendo em vista que os artigos serão divulgados no blog da escola.

Ao compararmos as 18 produções dos nove alunos, notamos que apenas seis alunos modificaram $\mathrm{O}$ texto significativamente, enquanto três alunos não $\mathrm{O}$ modificaram. Podemos, por hipótese, atribuir as poucas alterações ao comando de reescrita "Atenção: Você não vai escrever um novo texto. Você vai reescrever o texto anterior, não importando o quanto terá de alterá-lo". Esse comando difere dos comandos utilizados em outras pesquisas (Barros, 2012; Nascimento, Pereira, 2014) em que os alunos podiam escrever um novo texto na produção final. Nelas notamos mais evidências de alterações na comparação das primeiras e últimas versões.

Quanto à capacidade de ação, o destinatário estava implicado na maioria das produções iniciais (em cinco textos):

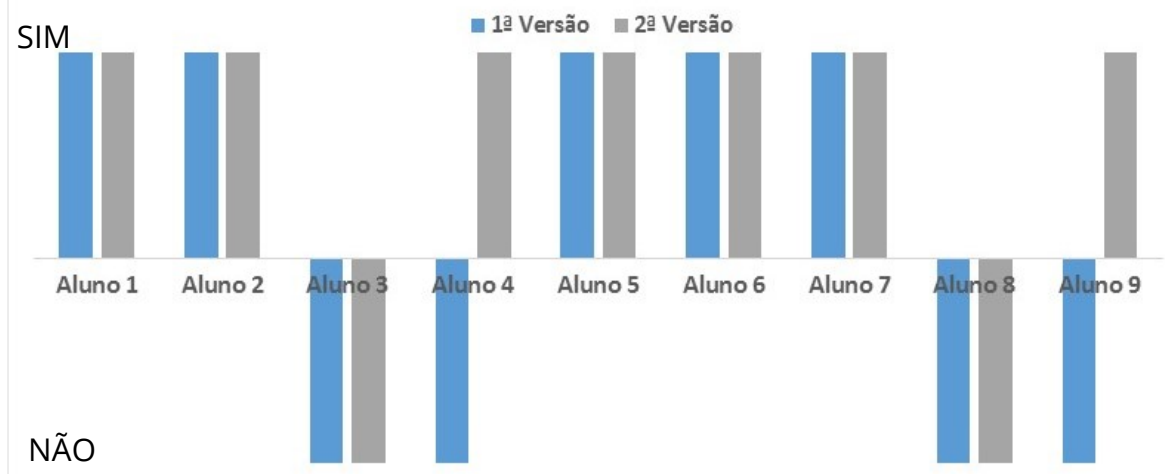

Figura 1 - Comparação das produções: destinatário implicado.

$\mathrm{Na}$ comparação, podemos verificar na Figura 1 que os alunos 3 e 8 não conseguiram implicar o destinatário em nenhuma das versões do artigo de opinião. Constatamos também que somente dois alunos (alunos 4 e 9) avançaram no quesito de implicação do destinatário. Não significa afirmar, entretanto, que as produções em que o destinatário já estava implicado permaneceram no mesmo patamar. Ao contrário, a representação do destinatário foi melhorada e, por isso, é possível afirmar que a SD, nesse caso, contribuiu para o aprimoramento da redação de sete alunos.

Convém ressaltar que a estratégia mais recorrente para este fim foram as perguntas retóricas. Dentre os sete alunos, seis utilizaram tal recurso para iniciar o desenvolvimento da análise do texto, garantindo a progressão textual de forma arregimentadora na demanda de respostas. 
No que se refere ao convencimento do leitor, nas produções iniciais apenas uma atendia a este item. Nas últimas, notamos avanços em quatro produções que conseguiram convencer o leitor. No entanto, o resultado geral não é satisfatório porque, após a didatização da $\mathrm{SD}$, cinco alunos não conseguiram atender a esse propósito inerente aos textos argumentativos (Figura 2).

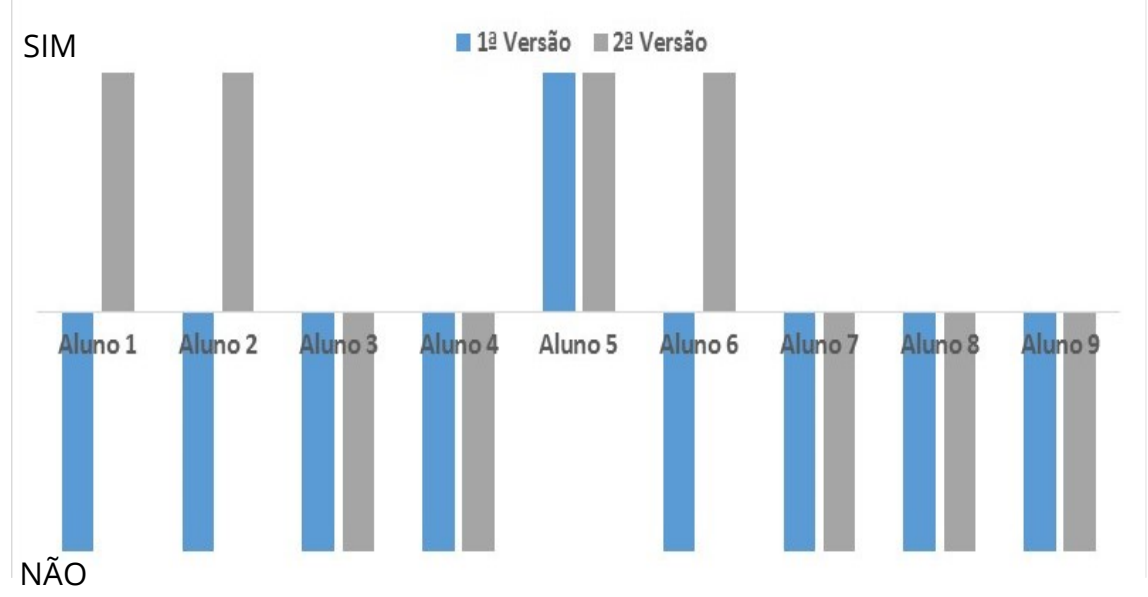

Figura 2 - Convencimento do leitor.

O comando da atividade de escrita teve como questão motivadora a descriminalização da maconha ou legalização das drogas; no entanto foi recorrente a confusão temática entre legalização, liberação e descriminalização das drogas e legalização e descriminalização da maconha.

Quadro 2 - Comparação das produções: tema das produções.

\begin{tabular}{|c|c|c|}
\hline \multicolumn{3}{|c|}{ Tema $^{12}$ das produções } \\
\hline Aluno & $1^{\mathrm{a}}$ versão & $2^{\mathrm{a}}$ versão \\
\hline 1 & Liberação das drogas & $\begin{array}{c}\text { Liberação das drogas e } \\
\text { descriminalização da maconha }\end{array}$ \\
\hline 2 & $\begin{array}{l}\text { Descriminalização da maconha } \\
\text { e legalização das drogas }\end{array}$ & $\begin{array}{l}\text { Descriminalização da maconha } \\
\text { e legalização das drogas }\end{array}$ \\
\hline 3 & Uso das drogas & $\begin{array}{c}\text { Tráfico, consumo e legalização } \\
\text { das drogas }\end{array}$ \\
\hline 4 & Uso das drogas & Uso das drogas \\
\hline 5 & $\begin{array}{c}\text { Legalização e liberação das } \\
\text { drogas }\end{array}$ & $\begin{array}{l}\text { Legalização e liberação das } \\
\text { drogas }\end{array}$ \\
\hline 6 & Liberação das drogas & Descriminalização das drogas \\
\hline 7 & Legalização das drogas & Legalização das drogas \\
\hline
\end{tabular}

\footnotetext{
${ }^{12}$ Nesta pesquisa o tema é entendido como "o sentido que nasce de todas as representações, referentes e unidades psicolinguísticas mobilizadas pelo agente-produtor no movimento textual e discursivo" (Ferraz, 2012, p. 58).
} 


\begin{tabular}{ccc}
\hline 8 & Legalização das drogas & $\begin{array}{c}\text { Descriminalização da maconha } \\
\text { e legalização das drogas }\end{array}$ \\
\hline 9 & Uso das drogas & Legalização das drogas \\
\hline
\end{tabular}

Conforme o Quadro 2, nas versões finais, podemos notar que apenas dois alunos atenderam ao comando de produção (alunos 7 e 9). Quatro alunos não atenderam ao comando e em três casos houve confusão temática entre legalização das drogas e descriminalização. É inegável que a diferença é muito tênue entre os termos; nesta análise, consideramos este fato porque durante a $\mathrm{SD}$ as diferenças terminológicas foram trabalhadas, por exemplo, nas atividades: 7-palestra sobre descriminalização da maconha e legalização das drogas; 9.3 - com o texto "Descriminalização da maconha: sim ou não? "; inclusive uma pergunta de interpretação escrita desse texto consistia em diferenciar descriminalização de legalização das drogas. Por outro lado, podemos deduzir que o fato de na SD muitos textos abordarem esses temas tão próximos pode ter colaborado para a confusão temática. Nesse contexto, o propósito comunicativo ficou prejudicado em sete versões finais.

No que se refere à capacidade discursiva, comparando as versões, poucos alunos utilizaram contra-argumentos (somente os alunos 1, 3, 4, 5 e 6), enquanto quatro não utilizaram esse recurso. Já a refutação foi utilizada por dois alunos (alunos 2 e 8) e não utilizada por sete. O tipo de argumento mais utilizado foi de causa e consequência. Houve registros de argumentos por exemplificação (alunos 1, 3 e 5); dados estatísticos (dois alunos: 1 e 3), comparação (aluno 8). A maioria dos argumentos foi embasada no senso-comum. Somente dois alunos alteraram os títulos de suas produções (alunos 3 e 9); inclusive, em alguns casos, dada a alteração do tema, o título perdeu a relação de sentido e não antecipou para o destinatário a questão que seria apresentada no texto.

Quanto à capacidade linguístico-discursiva, ao compararmos as versões é evidente o avanço dos alunos. Nas primeiras produções, de modo geral, havia muitos problemas no uso de organizadores textuais, sobretudo pela ausência de relação de sentido. Nas últimas versões, os alunos avançaram nesse sentido. Também é notório o uso de vozes, certamente um reflexo da didatização da SD em que a PC reiteradas vezes alerta para que utilizassem vozes na sustentação dos argumentos. No entanto, notamos também que muitos alunos utilizaram as vozes mais para cumprir um objetivo escolar do que para dialogar com elas durante o texto e/ou sustentar os argumentos.

Os alunos também evoluíram significativamente nas questões transversais da escrita, sobretudo na ortografia e pontuação. Entretanto, é preciso mencionar que a segunda versão foi digitada e essa melhora pode ter sido motivada pelas ferramentas de correções automáticas de programas de edição de texto.

Como análise final, notamos que cinco alunos evoluíram na capacidade de ação na comparação entre as versões do texto. Por outro lado, para quatro alunos $(44,4 \%)$ a SD não colaborou para a melhora nessa capacidade. Na capacidade discursiva, seis alunos melhoraram relativamente, sem muitos avanços $(66,6 \%)$. Já três alunos continuaram no mesmo nível discursivo da produção inicial. Diante dos resultados da capacidade linguístico-discursiva, assim como os resultados da pesquisa de CostaHübbes e Siminioni (2014), os alunos melhoraram significativamente. Introduziram 
mais vozes considerando o projeto do texto, utilizaram de modo mais apropriado as modalizações e organizadores textuais.

\section{CONSIDERAÇÕES FINAIS}

Com esta pesquisa, buscamos investigar o desenvolvimento das capacidades linguageiras de alunos do Ensino Médio por meio da produção de artigo de opinião, antes e após a didatização da SD. Pelas análises realizadas, constatamos que a SD constituiu uma boa alternativa para propiciar o desenvolvimento das capacidades de linguagem em alunos de um terceiro ano do Ensino Médio Noturno de uma escola pública estadual localizada em Dourados-MS.

Dado o contexto específico, concluímos que os alunos avançaram relativamente nas capacidades de ação e discursiva, ou seja, os alunos não melhoraram discursivamente o suficiente para que pudéssemos afirmar que todos produziram exemplares de artigo de opinião. Por outro lado, constatamos que todos os alunos avançaram na capacidade linguístico-discursiva.

Ademais, ainda é preciso considerar a não entrega das produções finais pela maioria dos alunos, ou seja, o envolvimento dos alunos e professores no processo de transposição didática não foi satisfatório. Dadas as poucas alterações realizadas nas produções finais, podemos inferir que os diálogos em sala de aula, sobretudo nos momentos de interpretação de texto, não se constituíram em momentos de reflexão no processo de reescrita.

Uma consequência interessante da SD foram os eventos de inclusão digital, a começar pela circulação do gênero no blog da escola. A ferramenta blog da escola já existia; no entanto, os alunos não tinham por hábito visitá-lo, muito menos para postar textos. Tanto a proposta de postagem das produções finais quanto as atividades virtuais fizeram com que os alunos utilizassem mais o laboratório de informática. Inclusive, as idas ao laboratório proporcionavam uma quebra da rotina escolar.

$\mathrm{Na}$ digitação das produções finais, muitos alunos aprenderam a trabalhar com editores de textos bem como a postar textos em blogs. Ressalta-se a presença em todas as aulas de um profissional específico da área de tecnologia educacional que colaborou nas questões técnicas de todas as atividades. Sabemos que nem todas as escolas dão acesso à internet para acesso a blogs, como aconteceu em Barros (2012). Nesse sentido, a estrutura da escola, seja com relação a questões estruturais ou de recursos humanos, favoreceu as atividades de letramento digital.

Ainda sobre o blog, merece destaque a preocupação das professoras PC e PP a respeito da circulação do gênero. Tal como foi feito por Costa-Hübbes (2009), a base da $\mathrm{SD}$, proposta pelos autores suíços, foi alterada à medida que foi inserida na proposta metodológica a etapa de circulação de gênero. Esse fato é visto como positivo, pois demonstra que as professoras foram capazes de readequar o conhecimento teórico para o contexto específico de ensino-aprendizagem.

Em última análise, é preciso considerar que a realidade brasileira é multifacetada. Por isso, sugerimos mais pesquisas de utilização da SD em turmas do período noturno, tendo em vista a particularidade de alunos e professores. O Ensino 
Médio Noturno, dentre as características peculiares apresentadas, tem carga horária total reduzida, considerando os dias letivos e comparando ao Ensino Médio diurno.

Cabe ainda salientar que, diante dos resultados alcançados, em menor grau do que esperávamos, sobretudo na capacidade discursiva, defendemos o conhecimento da prática de Língua Portuguesa arraigado nas práticas sociais de linguagem. Ressaltamos que não é possível generalizar a validade dos resultados obtidos, afinal é preciso considerar a heterogeneidade do contexto escolar.

Reiteramos a necessidade de continuidade de pesquisas que avaliem os procedimentos metodológicos utilizados para o desenvolvimento das capacidades linguageiras, sobretudo, na modalidade escrita da Língua Portuguesa, utilizados na formação de alunos do Ensino Médio. É preciso investir nas pesquisas do ensino de Língua Portuguesa nas escolas públicas, a fim de verificar as experiências, os avanços, os desafios, os retrocessos e traçar perspectivas de formação continuada para esses profissionais que atuam no contexto escolar.

\section{REFERÊNCIAS}

Barros EMD. Gestos de ensinar e de aprender gêneros textuais: a sequência didática como instrumento de mediação [tese]. Londrina: Centro de Letras e Ciências Humanas, Universidade Estadual de Londrina; 2012.

Bronckart JP. Atividade de linguagem, textos e discursos: por um interacionismo sociodiscursivo. Trad. Anna Rachel Machado e Péricles Cunha. 2ª ed. São Paulo: EDUC; 2007.

Bronckart JP. Atividades de linguagem, discurso e desenvolvimento humano. Anna Rachel Machado e Maria de Lourdes Meireles Matencio, organizadores. Trad. Anna Rachel Machado, et al. Campinas/SP: Mercado das Letras; 2006.

Cordeiro GS, Azevedo ICM, Mattos VL. Trabalhando com sequências didáticas: uma proposta de ensino e de análise de narrativas de aventuras de viagens. Calidoscópio. 2004;2(1):29-37.

Costa-Hübbes TC, Simioni CA. Sequência didática: uma proposta metodológica curricular de trabalho com os gêneros discursivos/textuais. In: Barros EMD, Rios-Registro ES, organizadores. Experiências com sequências didáticas de gêneros textuais. Campinas: Pontes; 2014. p. 15-39.

Dolz J, Noverraz M, Schneuwly B. Sequências didáticas para o oral e a escrita: apresentação de um procedimento. In: Schneuwly B, Dolz J. Gêneros orais e escritos na escola. Rojo R, Cordeiro GS, tradutores e organizadores. São Paulo: Mercado das Letras; 2004. p. 95-128.

Dolz J, Ronveaux C, Schneuwly B. Le synopsis - un outil pour analyser l'objet enseigné. In: Perrin MJ, Reuter Y, organizadores. Les méthodes de recherche en didactique. Actes du Premier Séminaire International de Juin 2005. Villeneuve d'Ascq: Presses Universitaires du Septentrion; 2006. p. 175-190.

Dolz J, Schneuwly B. Gêneros e progressão em expressão oral e escrita - elementos para reflexões sobre uma experiência suíça (francófona). In: Schneuwly B, Dolz J, organizadores. Gêneros orais e escritos na escola. Campinas: Mercado de Letras; 2004. p. 41-70.

Ferraz MRR. Formação continuada de professores e a transposição didática externa dos gêneros artigo de opinião e notícia [dissertação]. Mato Grosso do Sul: Faculdade de Comunicação Artes e Letras, Universidade Federal da Grande Dourados; 2012.

Lopes-Rossi MAG. A produção escrita de gêneros discursivos em sala de aula: aspectos teóricos e sequência didática. Signum: Estudos da Linguagem. 2012;15(3 esp.):223-245. 
Moita Lopes LP. Fotografias da linguística aplicada brasileira na modernidade recente. In: Moita Lopes LP, organizador. Linguística aplicada e a modernidade recente: Festschriff para Antonieta Celani. São Paulo: Parábola Editorial; 2013.

Nascimento EL, Pereira L. Mediação: instrumentos semióticos para aprendizagens e desenvolvimento. In: Barros EMD, Rios-Registro ES, organizadores. Experiências com sequências didáticas de gêneros textuais. Campinas: Pontes; 2014. p. 97-124.

Schneuwly B. Palavra e ficcionalização: um caminho para o ensino da linguagem oral. In: Schneuwly B, Dolz J, organizadores. Gêneros orais e escritos na escola. Campinas: Mercado de Letras; 2004. p. 128-147.

Schneuwly B, Dolz J. Os gêneros escolares: das práticas de linguagem aos objetos de ensino. In: Schneuwly B, Dolz J, organizadores. Gêneros orais e escritos na escola. Campinas: Mercado de Letras; 2004. p. 71-91. 


\section{ANexo}

Quadro: Sinopse dos módulos da sequência didática do gênero artigo de opinião.

\begin{tabular}{|c|c|c|c|}
\hline $\begin{array}{l}\text { Título das } \\
\text { atividades }\end{array}$ & $\begin{array}{l}\text { Objetivos das } \\
\text { professoras para } \\
\text { os alunos }\end{array}$ & Atividades & $\begin{array}{l}\text { Capacidades } \\
\text { de linguagem } \\
\text { implicadas e } \\
\text { horas/aula }\end{array}$ \\
\hline $\begin{array}{l}\text { 1- } \\
\text { Montagem de } \\
\text { painel com } \\
\text { vários gêneros }\end{array}$ & $\begin{array}{l}\text { - Apresentar diferentes } \\
\text { gêneros textuais aos } \\
\text { alunos para assimilação } \\
\text { do conceito de gêneros } \\
\text { textuais. } \\
\text { - Identificar o contexto } \\
\text { de produção. }\end{array}$ & $\begin{array}{l}\text { - Atividade em grupo: } \\
\text { identificação de textos } \\
\text { recebidos dentro de } \\
\text { envelopes. } \\
\text { - Atividade escrita de } \\
\text { identificação dos } \\
\text { aspectos contextuais: } \\
\text { quem escreveu os } \\
\text { textos; a quem são } \\
\text { dirigidos; qual objetivo e } \\
\text { em qual suporte os } \\
\text { textos foram veiculados. } \\
\text { - Atividade oral para a } \\
\text { correção das atividades. }\end{array}$ & $\begin{array}{l}\text { Ação } \\
2 \mathrm{~h} / \mathrm{a}\end{array}$ \\
\hline $\begin{array}{l}2- \\
\text { Debate sobre o } \\
\text { vídeo } \\
\text { "Liberdade de } \\
\text { expressão" }\end{array}$ & $\begin{array}{l}\text { - Sensibilizar os alunos } \\
\text { para a importância da } \\
\text { liberdade de expressão. } \\
\text { - Destacar a } \\
\text { importância do gênero } \\
\text { textual artigo de } \\
\text { opinião. } \\
\text { - Discutir os temas de } \\
\text { artigos de opinião. } \\
\text { - Apresentar aos alunos } \\
\text { o conceito de "papel } \\
\text { social". }\end{array}$ & $\begin{array}{l}\text { - Exibição do vídeo } \\
\text { "Liberdade de } \\
\text { expressão". } \\
\text { - Debate e produção } \\
\text { escrita sobre a } \\
\text { importância da liberdade } \\
\text { de expressão. }\end{array}$ & $\begin{array}{l}\text { Ação } \\
2 \mathrm{~h} / \mathrm{a}\end{array}$ \\
\hline $\begin{array}{l}\text { 3- } \\
\text { Leitura de } \\
\text { diversos } \\
\text { gêneros }\end{array}$ & $\begin{array}{l}\text { - Apresentar diferentes } \\
\text { gêneros textuais aos } \\
\text { alunos, com enfoque na } \\
\text { argumentação. } \\
\text { - Identificar opinião e } \\
\text { argumentos. }\end{array}$ & $\begin{array}{l}\text { - Em grupo: } \\
\text { interpretação de textos, } \\
\text { identificação do gênero } \\
\text { textual e elementos do } \\
\text { contexto de produção. } \\
\text { Atividade escrita de } \\
\text { interpretação textual, } \\
\text { com destaque para } \\
\text { identificação de } \\
\text { opiniões e argumentos } \\
\text { utilizados. }\end{array}$ & $\begin{array}{l}\text { Ação e } \\
\text { discursiva } \\
7 \mathrm{~h} / \mathrm{a}\end{array}$ \\
\hline
\end{tabular}




\begin{tabular}{|c|c|c|c|}
\hline $\begin{array}{l}\text { Título das } \\
\text { atividades }\end{array}$ & $\begin{array}{l}\text { Objetivos das } \\
\text { professoras para } \\
\text { os alunos }\end{array}$ & Atividades & $\begin{array}{l}\text { Capacidades } \\
\text { de linguagem } \\
\text { implicadas e } \\
\text { horas/aula }\end{array}$ \\
\hline $\begin{array}{l}\text { 4- } \\
\text { Vídeo e leitura }\end{array}$ & $\begin{array}{l}\text { - Mostrar semelhanças } \\
\text { e diferenças } \\
\text { contextuais, discursivas } \\
\text { e composicionais entre } \\
\text { crônica argumentativa e } \\
\text { artigo de opinião. } \\
\text { - Apontar os elementos } \\
\text { estruturais estáveis do } \\
\text { artigo de opinião. }\end{array}$ & $\begin{array}{l}\text { - Interpretação textual } \\
\text { com enfoque nos } \\
\text { seguintes objetos de } \\
\text { ensino: efeitos de } \\
\text { sentido (ironia, tempo } \\
\text { verbal e repetição de } \\
\text { termos), vocabulário, } \\
\text { enunciador, conteúdo } \\
\text { temático, posição social } \\
\text { e discursiva, } \\
\text { referenciação, pronomes } \\
\text { oblíquos, pessoais e } \\
\text { demonstrativos. } \\
\text { - Sistematização na } \\
\text { lousa dos argumentos } \\
\text { que revelam a opinião } \\
\text { de Luís Fernando } \\
\text { Veríssimo, autor do } \\
\text { texto “O povo”, e } \\
\text { hierarquização de } \\
\text { argumentos. } \\
\text { - Explicação oral sobre } \\
\text { a diferença entre título e } \\
\text { tema. } \\
\text { - Construção de um } \\
\text { painel sobre os } \\
\text { elementos estruturais } \\
\text { estáveis do artigo de } \\
\text { opinião e fixação do } \\
\text { painel na parede da sala. }\end{array}$ & $\begin{array}{l}\text { Ação, } \\
\text { discursiva e } \\
\text { linguístico- } \\
\text { discursiva } \\
3 \mathrm{~h} / \mathrm{a}\end{array}$ \\
\hline $\begin{array}{l}\text { 5- } \\
\text { Loteria dos } \\
\text { gêneros } \\
\text { dissertação } \\
\text { escolar e artigo } \\
\text { de opinião }\end{array}$ & $\begin{array}{l}\text { - Trabalhar, } \\
\text { sistematicamente, } \\
\text { diferenças e } \\
\text { semelhanças } \\
\text { contextuais, discursivas } \\
\text { e estruturais entre } \\
\text { dissertação escolar e } \\
\text { artigo de opinião. } \\
\text { - Apontar os elementos } \\
\text { estáveis do artigo de } \\
\text { opinião. }\end{array}$ & $\begin{array}{l}\text { - Associação de } \\
\text { elementos } \\
\text { composicionais } \\
\text { relativamente estáveis } \\
\text { dos gêneros artigo de } \\
\text { opinião e dissertação } \\
\text { escolar. }\end{array}$ & $\begin{array}{l}\text { Ação, } \\
\text { discursiva e } \\
\text { linguístico- } \\
\text { discursiva } \\
2 \mathrm{~h} / \mathrm{a}\end{array}$ \\
\hline
\end{tabular}




\begin{tabular}{|c|c|c|c|}
\hline $\begin{array}{l}\text { Título das } \\
\text { atividades }\end{array}$ & $\begin{array}{l}\text { Objetivos das } \\
\text { professoras para } \\
\text { os alunos }\end{array}$ & Atividades & $\begin{array}{l}\text { Capacidades } \\
\text { de linguagem } \\
\text { implicadas e } \\
\text { horas/aula }\end{array}$ \\
\hline $\begin{array}{l}\text { 6- } \\
\text { A questão } \\
\text { polêmica }\end{array}$ & $\begin{array}{l}\text { - Identificar uma } \\
\text { questão polêmica e o } \\
\text { conteúdo temático dos } \\
\text { artigos de opinião } \\
\text { selecionados. } \\
\text { - Analisar oralmente a } \\
\text { página completa de } \\
\text { jornais de circulação } \\
\text { local, dando enfoque ao } \\
\text { artigo de opinião. } \\
\text { - Estabelecer } \\
\text { diferenças e } \\
\text { semelhanças (de } \\
\text { natureza linguístico- } \\
\text { discursiva e do ponto } \\
\text { de vista da estrutura } \\
\text { composicional) entre: } \\
\text { artigo de opinião, } \\
\text { editorial, cartum e } \\
\text { charge. }\end{array}$ & $\begin{array}{l}\text { - Análise, em duplas, de } \\
\text { exemplares de jornais de } \\
\text { circulação local. } \\
\text { - Atividade escrita de } \\
\text { identificação dos } \\
\text { aspectos contextuais e } \\
\text { discursivos do artigo de } \\
\text { opinião. } \\
\text { - Análise oral de página } \\
\text { completa de jornal em } \\
\text { que os artigos de } \\
\text { opinião foram } \\
\text { publicados. } \\
\text { - Exposição na lousa } \\
\text { das diferenças e } \\
\text { semelhanças entre artigo } \\
\text { de opinião, cartum, } \\
\text { charge e editorial. } \\
\text { - Tarefa de casa: Trazer } \\
\text { para a próxima aula uma } \\
\text { charge e um cartum; } \\
\text { justificar, por escrito, a } \\
\text { razão da classificação. }\end{array}$ & $\begin{array}{l}\text { Ação e } \\
\text { discursiva } \\
2 \mathrm{~h} / \mathrm{a}\end{array}$ \\
\hline $\begin{array}{l}\text { 7- Discutindo a } \\
\text { questão } \\
\text { polêmica }\end{array}$ & $\begin{array}{l}\text { - Aprofundar o tema } \\
\text { descriminalização da } \\
\text { maconha e legalização } \\
\text { das drogas, para que os } \\
\text { estudantes construam } \\
\text { argumentos a serem } \\
\text { utilizados na } \\
\text { textualização do artigo } \\
\text { de opinião. }\end{array}$ & $\begin{array}{l}\text { - Palestra sobre } \\
\text { descriminalização da } \\
\text { maconha e legalização } \\
\text { das drogas. } \\
\text { - Atividade virtual: } \\
\text { apresentação e discussão } \\
\text { do trailer do } \\
\text { documentário: } \\
\text { "Quebrando o tabu"13. }\end{array}$ & $\begin{array}{l}\text { Ação e } \\
\text { discursiva } \\
3 \mathrm{~h} / \mathrm{a}\end{array}$ \\
\hline
\end{tabular}

${ }^{13}$ Data de produção: outubro de 2011. Disponível em: https://www.youtube.com/watch?v=mk3MLkXCOYo. 


\begin{tabular}{|c|c|c|c|}
\hline $\begin{array}{l}\text { Título das } \\
\text { atividades }\end{array}$ & $\begin{array}{l}\text { Objetivos das } \\
\text { professoras para } \\
\text { os alunos }\end{array}$ & Atividades & $\begin{array}{l}\text { Capacidades } \\
\text { de linguagem } \\
\text { implicadas e } \\
\text { horas/aula }\end{array}$ \\
\hline $\begin{array}{l}\text { 8- Conhecendo } \\
\text { o tema - as } \\
\text { etapas da } \\
\text { Cannabis Sativa }\end{array}$ & $\begin{array}{l}\text { - Detalhar aspectos } \\
\text { históricos, geográficos e } \\
\text { químicos da maconha, } \\
\text { as etapas do processo } \\
\text { de criminalização, as } \\
\text { indicações e } \\
\text { contraindicações } \\
\text { medicinais. }\end{array}$ & $\begin{array}{l}\text { - Discussão de um } \\
\text { vídeo do Programa: } \\
\text { "Um pé de quê?", } \\
\text { veiculado pelo Canal } \\
\text { Futura }^{14} \text {. }\end{array}$ & $\begin{array}{l}\text { Ação } \\
1 \mathrm{~h} / \mathrm{a}\end{array}$ \\
\hline $\begin{array}{l}\text { 9- } \\
\text { A arquitetura } \\
\text { do artigo de } \\
\text { opinião: } \\
\text { reconhecendo } \\
\text { argumentos } \\
\text { favoráveis e } \\
\text { contrários }\end{array}$ & $\begin{array}{l}\text { - Caracterizar o plano } \\
\text { textual global. } \\
\text { - Ressaltar as diferentes } \\
\text { opiniões a respeito da } \\
\text { descriminalização da } \\
\text { maconha e legalização } \\
\text { das drogas. }\end{array}$ & $\begin{array}{l}\text { - Interpretação escrita } \\
\text { de um fragmento de } \\
\text { uma carta de leitor. } \\
\text { - Correção oral das } \\
\text { atividades. }\end{array}$ & $\begin{array}{l}\text { Discursiva } \\
2 \mathrm{~h} / \mathrm{a}\end{array}$ \\
\hline $\begin{array}{l}9.1 \\
\text { Atividade } \\
\text { virtual: } \\
\text { Contraposição } \\
\text { de argumentos }\end{array}$ & $\begin{array}{l}\text { - Elaborar contra- } \\
\text { argumentos. }\end{array}$ & $\begin{array}{l}\text { - Aula interativa. Um } \\
\text { palestrante foi } \\
\text { convidado para } \\
\text { responder às questões } \\
\text { dos alunos, via } \\
\text { webconferência. }\end{array}$ & $\begin{array}{l}\text { Discursiva } \\
2 \mathrm{~h} / \mathrm{a}\end{array}$ \\
\hline $\begin{array}{l}9.2- \\
\text { Reconhecendo } \\
\text { argumentos } \\
\text { favoráveis e } \\
\text { contrários II }\end{array}$ & $\begin{array}{l}\text { - Mostrar aos alunos a } \\
\text { estrutura do texto: } \\
\text { contextualização, } \\
\text { premissa, argumentos, } \\
\text { contra-argumentos, } \\
\text { avaliação e conclusão. } \\
\text { - Identificar as vozes } \\
\text { utilizadas no } \\
\text { desenvolvimento do } \\
\text { texto. }\end{array}$ & $\begin{array}{l}\text { - Interpretação textual } \\
\text { escrita com foco } \\
\text { específico na } \\
\text { identificação da } \\
\text { estrutura composicional } \\
\text { do texto e das vozes } \\
\text { utilizadas. } \\
\text { - Correção oral dos } \\
\text { exercícios. }\end{array}$ & $\begin{array}{l}\text { Linguístico- } \\
\text { discursiva } \\
2 \mathrm{~h} / \mathrm{a}\end{array}$ \\
\hline
\end{tabular}

${ }^{14}$ Canal Futura. Programa "Um pé de quê?". Data de exibição do Programa: 19/11/2008.

Disponível em: https: / $/$ www.youtube.com/watch?v=vL3gFVTZFf0\&t=21s. 


\begin{tabular}{|c|c|c|c|}
\hline $\begin{array}{l}\text { Título das } \\
\text { atividades }\end{array}$ & $\begin{array}{l}\text { Objetivos das } \\
\text { professoras para } \\
\text { os alunos }\end{array}$ & Atividades & $\begin{array}{l}\text { Capacidades } \\
\text { de linguagem } \\
\text { implicadas e } \\
\text { horas/aula }\end{array}$ \\
\hline $\begin{array}{l}9.3- \\
\text { Reconhecendo } \\
\text { argumentos } \\
\text { favoráveis e } \\
\text { contrários III }\end{array}$ & $\begin{array}{l}\text { - Fazer com que os } \\
\text { alunos identifiquem a } \\
\text { arquitetura do texto. }\end{array}$ & $\begin{array}{l}\text { - Interpretação escrita } \\
\text { com foco na } \\
\text { identificação da } \\
\text { estrutura do texto. } \\
\text { - Análise de uma capa } \\
\text { da revista Cláudia. }\end{array}$ & $\begin{array}{l}\text { Discursiva } \\
1 \mathrm{~h} / \mathrm{a}\end{array}$ \\
\hline $\begin{array}{l}9.3 .1 \text { - } \\
\text { Atividade } \\
\text { virtual: } \\
\text { Discussão de } \\
\text { questão } \\
\text { polêmica }\end{array}$ & $\begin{array}{l}\text { - Refletir a respeito da } \\
\text { dependência física e } \\
\text { psíquica das drogas. } \\
\text { - Aprofundar o tema } \\
\text { drogas para que } \\
\text { pudessem concluir se } \\
\text { são favoráveis ou } \\
\text { contrários à } \\
\text { descriminalização da } \\
\text { maconha e à legalização } \\
\text { das drogas. }\end{array}$ & $\begin{array}{l}\text { - Exibição de: } \\
\text { - Vídeo de uma } \\
\text { reportagem exibida no } \\
\text { programa "Fantástico"; } \\
\text { - Cenas da novela “O } \\
\text { Clone" e } \\
\text { - Entrevista com o } \\
\text { comentarista de futebol } \\
\text { Walter Casagrande no } \\
\text { programa "Domingão } \\
\text { do Faustão". } \\
\text { - Discussão oral dos } \\
\text { vídeos. } \\
\text { - Tarefa de casa: } \\
\text { construir um parágrafo } \\
\text { sobre as consequências } \\
\text { da dependência química } \\
\text { e postar no blog da } \\
\text { escola. }\end{array}$ & $\begin{array}{l}\text { Discursiva } \\
2 \mathrm{~h} / \mathrm{a}\end{array}$ \\
\hline $\begin{array}{l}10- \\
\text { A organização } \\
\text { da estrutura de } \\
\text { um artigo de } \\
\text { opinião: } \\
\text { reconhecendo } \\
\text { os elementos } \\
\text { estruturais do } \\
\text { artigo de } \\
\text { opinião }\end{array}$ & $\begin{array}{l}\text { - Evidenciar os } \\
\text { elementos } \\
\text { composicionais do } \\
\text { artigo de opinião. }\end{array}$ & $\begin{array}{l}\text { - Interpretação de } \\
\text { fragmentos de texto e } \\
\text { associação a elementos } \\
\text { composicionais do } \\
\text { gênero artigo de } \\
\text { opinião. }\end{array}$ & $\begin{array}{l}\text { Discursiva } \\
1 \mathrm{~h} / \mathrm{a}\end{array}$ \\
\hline
\end{tabular}




\begin{tabular}{|c|c|c|c|}
\hline $\begin{array}{l}\text { Título das } \\
\text { atividades }\end{array}$ & $\begin{array}{l}\text { Objetivos das } \\
\text { professoras para } \\
\text { os alunos }\end{array}$ & Atividades & $\begin{array}{l}\text { Capacidades } \\
\text { de linguagem } \\
\text { implicadas e } \\
\text { horas/aula }\end{array}$ \\
\hline $\begin{array}{l}10.1 \text { - } \\
\text { Reconhecendo } \\
\text { os elementos } \\
\text { estruturais do } \\
\text { artigo de } \\
\text { opinião II }\end{array}$ & $\begin{array}{l}\text { - Identificar a estrutura } \\
\text { composicional do } \\
\text { artigo de opinião: } \\
\text { contextualização, } \\
\text { premissa, argumentos, } \\
\text { contra-argumentos, } \\
\text { refutação, avaliação, } \\
\text { negociação e conclusão. } \\
\text { - Identificar as vozes e } \\
\text { exemplificar alguns } \\
\text { usos de modalização. }\end{array}$ & $\begin{array}{l}\text { - Interpretação de dois } \\
\text { textos com o objetivo } \\
\text { de identificar elementos } \\
\text { composicionais, vozes e } \\
\text { modalização. }\end{array}$ & $\begin{array}{l}\text { Discursiva e } \\
\text { linguístico- } \\
\text { discursiva } \\
2 \mathrm{~h} / \mathrm{a}\end{array}$ \\
\hline $\begin{array}{l}\text { 11- } \\
\text { Diversificando } \\
\text { os argumentos: } \\
\text { o movimento } \\
\text { dialógico do } \\
\text { artigo de } \\
\text { opinião }\end{array}$ & $\begin{array}{l}\text { - Identificar as vozes } \\
\text { que perpassam os } \\
\text { textos e reconhecer sua } \\
\text { função e o sentido que } \\
\text { elas direcionam. }\end{array}$ & $\begin{array}{l}\text { - Interpretação oral e } \\
\text { escrita de dois textos, } \\
\text { focando as vozes e os } \\
\text { efeitos de sentido } \\
\text { possíveis. }\end{array}$ & $\begin{array}{l}\text { Discursiva e } \\
\text { linguístico- } \\
\text { discursiva } \\
1 \mathrm{~h} / \mathrm{a}\end{array}$ \\
\hline $\begin{array}{l}11.1- \\
(\mathrm{Re}) \\
\text { conhecendo os } \\
\text { tipos de } \\
\text { argumentos }\end{array}$ & $\begin{array}{l}\text { - Apresentar os } \\
\text { diferentes tipos de } \\
\text { argumentos que um } \\
\text { articulista pode utilizar } \\
\text { para comprovar sua } \\
\text { tese. }\end{array}$ & $\begin{array}{l}\text { - Localização dos tipos } \\
\text { de argumentos em dois } \\
\text { textos. }\end{array}$ & $\begin{array}{l}\text { Discursiva } \\
1 \mathrm{~h} / \mathrm{a}\end{array}$ \\
\hline $\begin{array}{l}\text { 12- Refutando } \\
\text { argumentos }\end{array}$ & $\begin{array}{l}\text { - Discutir o } \\
\text { movimento discursivo } \\
\text { de rejeição de teses ou } \\
\text { argumentos opostos } \\
\text { aos do autor de um } \\
\text { artigo de opinião. }\end{array}$ & $\begin{array}{l}\text { - Interpretação textual } \\
\text { oral de dois textos. }\end{array}$ & $\begin{array}{l}\text { Discursiva } \\
1 \mathrm{~h} / \mathrm{a}\end{array}$ \\
\hline
\end{tabular}




\begin{tabular}{|c|c|c|c|}
\hline $\begin{array}{l}\text { Título das } \\
\text { atividades }\end{array}$ & $\begin{array}{l}\text { Objetivos das } \\
\text { professoras para } \\
\text { os alunos }\end{array}$ & Atividades & $\begin{array}{l}\text { Capacidades } \\
\text { de linguagem } \\
\text { implicadas e } \\
\text { horas/aula }\end{array}$ \\
\hline $\begin{array}{l}12.1- \\
\text { Identificando } \\
\text { argumentos } \\
\text { refutáveis }\end{array}$ & $\begin{array}{l}\text { - Identificar } \\
\text { argumentos refutáveis. }\end{array}$ & $\begin{array}{l}\text { - Interpretação escrita } \\
\text { com foco na } \\
\text { identificação de } \\
\text { refutação de } \\
\text { argumentos. } \\
\text { - Correção oral dos } \\
\text { exercícios. } \\
\text { - Elaboração de um } \\
\text { parágrafo fazendo uso } \\
\text { da refutação. }\end{array}$ & $\begin{array}{l}\text { Discursiva } \\
1 \mathrm{~h} / \mathrm{a}\end{array}$ \\
\hline $\begin{array}{l}13- \\
\text { Explorando a } \\
\text { linguagem do } \\
\text { artigo de } \\
\text { opinião: } \\
\text { anáforas, } \\
\text { elipses e os } \\
\text { sentidos dos } \\
\text { organizadores } \\
\text { textuais }\end{array}$ & $\begin{array}{l}\text { - Trabalhar os } \\
\text { organizadores textuais: } \\
\text { anáforas, elipses e } \\
\text { organizadores textuais. }\end{array}$ & $\begin{array}{l}\text { - Localização de } \\
\text { anáforas, elipses e } \\
\text { elementos de } \\
\text { referenciação em uma } \\
\text { notícia. } \\
\text { - Em grupo: } \\
\text { organização de períodos } \\
\text { distribuídos pelas } \\
\text { professoras, articulando } \\
\text { as partes dos textos com } \\
\text { conectivos adequados } \\
\text { ao sentido. Substituição } \\
\text { de organizadores } \\
\text { textuais mantendo o } \\
\text { sentido original; se } \\
\text { necessário, } \\
\text { reorganização do } \\
\text { período. }\end{array}$ & $\begin{array}{l}\text { Linguístico- } \\
\text { discursiva } \\
3 \mathrm{~h} / \mathrm{a}\end{array}$ \\
\hline $\begin{array}{l}13.1-\text { A } \\
\text { variedade } \\
\text { padrão da } \\
\text { língua }\end{array}$ & $\begin{array}{l}\text { - Refletir sobre o nível } \\
\text { de linguagem nos } \\
\text { gêneros. }\end{array}$ & $\begin{array}{l}\text { - Reprodução da música } \\
\text { "Tem alguém aî" de } \\
\text { Gabriel Pensador. } \\
\text { - Interpretação escrita } \\
\text { da música com foco em: } \\
\text { efeitos de sentido, } \\
\text { reconhecimento da voz } \\
\text { do enunciador, } \\
\text { repetição voluntária de } \\
\text { palavras, organizadores } \\
\text { textuais, vozes sociais, } \\
\text { desvios linguísticos, } \\
\text { relação de sentido entre } \\
\text { título e texto. }\end{array}$ & $\begin{array}{l}\text { Discursiva e } \\
\text { linguístico- } \\
\text { discursiva } \\
1 \mathrm{~h} / \mathrm{a}\end{array}$ \\
\hline
\end{tabular}




\begin{tabular}{|c|c|c|c|}
\hline $\begin{array}{l}\text { Título das } \\
\text { atividades }\end{array}$ & $\begin{array}{l}\text { Objetivos das } \\
\text { professoras para } \\
\text { os alunos }\end{array}$ & Atividades & $\begin{array}{l}\text { Capacidades } \\
\text { de linguagem } \\
\text { implicadas e } \\
\text { horas/aula }\end{array}$ \\
\hline $\begin{array}{l}13.2 \text { - } \\
\text { Atividade } \\
\text { virtual: posição } \\
\text { do autor e os } \\
\text { argumentos }\end{array}$ & $\begin{array}{l}\text { - Fazer com que os } \\
\text { alunos identifiquem a } \\
\text { posição do autor e os } \\
\text { argumentos. }\end{array}$ & $\begin{array}{l}\text { - Leitura e interpretação } \\
\text { oral de dois textos. } \\
\text { - Preenchimento de um } \\
\text { quadro com posição } \\
\text { enunciativa do agente- } \\
\text { produtor e argumentos } \\
\text { utilizados no texto. } \\
\text { - Atividade escrita: } \\
\text { refutação de argumentos } \\
\text { dos enunciadores. } \\
\text { - Atividade escrita: } \\
\text { refutação dos } \\
\text { argumentos dos colegas. } \\
\text { - Construção de um } \\
\text { parágrafo para ser } \\
\text { postado no blog da } \\
\text { escola. }\end{array}$ & $\begin{array}{l}\text { Discursiva } \\
1 \mathrm{~h} / \mathrm{a}\end{array}$ \\
\hline $\begin{array}{l}\text { 14- }(\mathrm{Re}) \\
\text { conhecendo os } \\
\text { mecanismos } \\
\text { enunciativos }\end{array}$ & $\begin{array}{l}\text { - Trabalhar os } \\
\text { mecanismos } \\
\text { enunciativos: pessoa, } \\
\text { modos e tempo verbais, } \\
\text { modalizadores } \\
\text { (adjetivos, advérbios, } \\
\text { artigos, locuções } \\
\text { verbais). }\end{array}$ & $\begin{array}{l}\text { - Reconhecimento dos } \\
\text { mecanismos } \\
\text { enunciativos em dois } \\
\text { textos. } \\
\text { - Correção oral da } \\
\text { atividade. }\end{array}$ & $\begin{array}{l}\text { Linguístico- } \\
\text { discursiva } \\
1 \mathrm{~h} / \mathrm{a}\end{array}$ \\
\hline $\begin{array}{l}15-\text { Reescrita } \\
\text { do texto }\end{array}$ & $\begin{array}{l}\text { - Relembrar o que foi } \\
\text { visto em sala de aula } \\
\text { sobre o gênero artigo } \\
\text { de opinião. } \\
\text { - Produção final do } \\
\text { artigo de opinião; } \\
\text { utilização da lista de } \\
\text { controle para promover } \\
\text { a autocorreção. }\end{array}$ & $\begin{array}{l}\text { - Produção textual. } \\
\text { - Lista de controle. }\end{array}$ & $\begin{array}{l}\text { Ação, } \\
\text { discursiva e } \\
\text { linguístico- } \\
\text { discursiva } \\
1 \mathrm{~h} / \mathrm{a}\end{array}$ \\
\hline $\begin{array}{l}\text { 16- Publicação } \\
\text { do artigo de } \\
\text { opinião e } \\
\text { avaliação do } \\
\text { trabalho com a } \\
\text { SD }\end{array}$ & $\begin{array}{l}\text { - Orientar a publicação } \\
\text { dos artigos de opinião } \\
\text { no blog da escola. } \\
\text { - Avaliar o trabalho } \\
\text { realizado com a SD. }\end{array}$ & $\begin{array}{l}\text { - Publicação dos artigos } \\
\text { de opinião. } \\
\text { - Roda de conversa. }\end{array}$ & $\begin{array}{l}\text { Ação, } \\
\text { discursiva e } \\
\text { linguístico- } \\
\text { discursiva } \\
1 \mathrm{~h} / \mathrm{a}\end{array}$ \\
\hline
\end{tabular}

